\title{
RECONHECIMENTO DA REPÚBLICA BRASILEIRA PELA RÚSSIA: ALGUNS ASPECTOS
}

\author{
Sandra M. L. Brancato*
}

No periodo imediatamente posterior à proclamação da república no Brasil as relações entre esta e a Rússia atravessaram momentos difíceis. A velha monarquia não só resistia em reconhecer a nova república, como até mesmo dificultava a manuten. ção das relações oficiosas recíprocas. Devido a este quadro, a permanência do Conselheiro Alfredo Sérgio Teixeira de Macedo como Enviado Extraordinário e Ministro Plenipotenciário brasileiro na Rússia tornou-se problemática.

O objetivo deste trabalho é revelar parte de uma documentação inédita e bastante curiosa sobre o reconhecimento da república pela Rússia, além de examinar as dificuldades enfrentadas por Teixeira de Macedo no desempenho de sua função em um momento especialmente delicado das relações Brasil/Rússia. Examinar-se-á também alguns aspectos da tradicional sociedade russa que interferiram diretamente no comportamento de seu governo em relação ao representante brasileiro, e ainda como se deu, finalmente, o reconhecimento da república pelo governo do Czar Alexandre III, fazendo com que a Rússia viesse a ser o último país a estabelecer relações diplomáticas com a nova república americana.

* Curso de Pós-Graduação em História - IFCH. Pontificia Universidade Católica do Rio Grande do Sul. Porto Alegre - RS.

Estudos Ibero-Americanos. PUCRS, v. XVIII, n. 2, p. 85-91, dezembro, 1992 


\section{OS PRIMEIROS CONTACTOS OFICIAIS DA NOVA REPÚBLICA}

Ao receber a circular do governo brasileiro de 19 de novembro de 1889 que comunicava a mudança de regime no Brasil, Teixeira de Macedo apressou-se em enviá. lo a Giers, Ministro dos Negócios Estrangeiros da Rússia. Esta circular chegou a São Petersburgo somente a 16 de dezembro de 1889 , quando então o governo russo deveria manifestar-se oficialmente sobre suas relaçōes com o Brasil. Contudo, segundo relata Teixeira de Macedo, as autoridades, reticentes, protelavam uma definição. ${ }^{1}$ Somente devido a sua incansável insistência a posiçâo Russa ficou conhecida, depois de uma conferência oficiosa que manteve com Giers, quando este esclareceu que seu governo deixaria a comunicação brasileira sem resposta até conhecer a conduta ado. tada por outros Estados. No entanto, adiantara o ministro, que seu pais certamente nào seria dos primeiros a reconhecer a república, nem, necessariamente, o último. ${ }^{2}$

A partir deste momento Teixeira de Macedo passou a enfrentar situações constrangedoras que tendiam a só agravar cada vez mais, como ele mesmo informava em correspondência a seus superiores.

\section{AS DIFICULDADES DE TEIXEIRA DE MACEDO}

Na conferência oficiosa entre Teixeira de Macedo e Giers anteriormente referida, este ministro, em nome da amizade que o ligava ao primeiro, foi muito sincero ao externar sua opinião, conforme seguia informado Teixeira de Macedo. Para o Ministro russo a presença do brasileiro "haveria proximamente embaraçar o governo", uma vez que o Czar deveria dentro de pouco receber os representantes dos países amigos, como tradicionalmente costumava fazer nas festas de fim de ano.

A dimensão do problema pode ser avaliada pelo depoimento de Teixeira de Macedo: "fez-me comprehender S. Ex. a importancia desta cerimonia feita sempre com o maior aparato: as embaixadas e as legaçōes fazem timbre de se apresentar em au grand complet, algumas com um pessoal de doze individuos, não comparecendo as senhoras a esta cerimonia. O Czar dirige-se ao Corpo diplomatico alinhado e troca algumas palavras com cada chefe de missão, que lhe apresenta em seguida os membros della novamente chegados. Excluir o Brasil desta cerimonia é não considera-lo no número das nações amigas da Rússia; convidar o seu representante officioso é, tratalo no seu carater official, o que importa o reconhecimento formal do seu Governo. Uma e outra cousa deseja o Governo da Russia evitar não estando menos em jogo os nossos brios. 
Ante situação tâo constrangedora Teixeira de Macedo sugere, em telegrama a Quintino Bocayuva, uma saída honrosa; "Convem telegraphar [minha] remoção ou autorizar [minha] ausencia."

Posteriormente, cauteloso, Teixeira de Macedo esclarece a posição tomada: "se tomei a liberdade de indicar no fim do meu telegrama a medida a tomar não foi que eu de modo algum quizesse insinuar o que a mim podia convir mas tão somente porque entendi assim deixar mais patente a posição em que me achava cousa difficil de fazer em poucas palavras como o uso do telefrapho exige."

A argumentação de Teixeira de Macedo não sensibilizou o governo brasileiro. Assim, sem nenhuma sutileza, o Ministro volta a pressionar:"... a vista das ordens de V. Ex. não deixei o meu posto e realmente tinha-me sido difficil porque tenho estado doente ora de cama ora melhor e de pé mas nunca em estado de poder emprehender uma viagem. Ha males porem que vem para bem. O público está sciente do meu estado e pude assim com alguma apparencia de sinceridade escrever na $4^{a}$ feira 27 de dezembro russo ao Snr. de Giers pedindo-lhe que me excusasse junto de S. M. O Czar por não comparecer a cerimonia do $1^{\circ}$ anno. Assim ficarão por ora salvas as suscep. tibilidades officiaes respectivas. Outras recepções, porem, embora de menos cathegoria e significação hão de succeder-se continuando sempre melindrosa a minha posiçâo."3

A falta de vínculos mais sólidos, tanto a nível econômico como político, entre o Brasil e a Rússia também não justificavam, na opinião de Teixeira de Macedo, a manutenção da legação que "tornava-se ociosa e actualmente embaraçosa." A falta de, identidade entre os regimes pesava tanto na Rússia que fugia a compreensão daqueles que não conhecessem mais de perto a hierarquia de valores que regia seu governo. Consciente disto, informa Teixeira de Macedo: "É preciso que o Governo da República se compenetre de que as sympathias da Rússia pelo Brasil tinhão por unico fundamento as nossas antigas instituições monarchicas que suppunha tão solidas com as proprias. Uma vez estas desapparecidas entramos para o Czar, no rol das nações cuja a amizade tem por base, não a paz mas o armisticio, estando nas mútuas relações substituidas a sympathia pelo desdem mais ou menos apparente segundo os interesses em jogo."

A atitude das autoridades russas vinham confirmando os juizos de Teixeira de Macedo. Em 27 de janeiro de 1890, permanecendo ainda em seu posto, apesar dos constantes apelos que fizera para ser transferido, apresenta novas evidências de que sua presença tornava-se incomoda também para o governo russo: "Conversando com o Snr. de Giers no dia 3 do corrente russo correspondente ao nosso dia 15, confirmoume S. Ex. que minha excusa por molestia tinha tirado o Governo Russo do embaraço 
em que se achou porquanto era-the impossivel tratar-me como representante do Brasil na situação em que se achava o nosso paiz.'4

Para melhor entendimento da situaçâo, Teixeira de Macedo vai fornecendo informações sobre a corte russa sem as quais certamente haveria dificuldades para as autoridades brasileiras compreenderem a extensão dos problemas que enfrentava e o quanto estes afetavam a própria dignidade do país que representava: "Estas questōes de etiqueta podem no nosso paíz parecer de importancia secundaria, mas aqui não é assim, e nossos sentimentos democraticos, de que alias sempre partilhei, não se impõe em um centro inspirado de ideais absolutamente oppostas. Minha presença ou ausencia mal justificada, em certas cerimonias officiaes, constitue escandalo publico que reverte contra nosso paiz, attingindo a sua dignidade."

As situaçôes constrangedoras continuavam se acumulando cada vez mais, aumentando as razões apresentadas por Teixeira de Macedo 5 para justificar sua transferência: "No dia 6 de janeiro russo houve a grande festa religiosa da benção das aguas, a que o Corpo diplomatico assiste como curioso das janellas do palacio, mas traz a farda porque almoça depois com alguns altos funcionarios da Corte que fazem-the as honras em nome do Czar. A esta cerimonia fui convidado como simples particular, mas entendi preferivel prolongar a minha molestia, tanto mais que nas suas confidencias o Snr. de Giers tinha-me dito que S. M. o Czar preferia nào encontrar-se comigo onde a farda é de rigor, para nem ver-me com ella nem sem, enquanto o novo estado de cousas no nosso paiz não tiver sido reconhecido. Assim era eu tolerado nesta festa, como quisesse apresentar-me, porque S. M. nâo se aproximaria do Corpo diplomatico. No dia 14 russo teve lugar o chamado grande baile da Corte considerado de maior gala, para o qual são convidados 5000 pessoas. A minha posição era a mesma que no dia $1^{9}$ do anno. Para evitar um certo ridiculo, não renovei a minha excusa por doente, mas, não tendo sido convidado considerei-a como persistente. ${ }^{6}$

Por fim, os apelos de Teixeira de Macedo foram ouvidos, sendo autorizada sua saida da Rússia. Em 12 de agosto de 1890, já no Rio de Janeiro, envia um relatório final ao Ministério das Relações Exteriores dando conta de seus últimos atos antes de deixar São Petersburgo. Por uma deferência especial o Czar assentiu em recebêtlo numa audiência particular, o que foi entendido como um ato de benevolência a sua pessoa e não como uma tentativa de reaproximação com o Brasil. Na audiência, relata Teixeira de Macedo, "fui muito questionado a respeito dos negócios do nosso paiz e pude notar em toda a linguagem e nas apreciações de S. M. uma escolha de expressões atenciosas que jamais podião ferir quer a situação política presente quer a passada do nosso paiz. Suas expressões para comigo forĩo das que mais podião 
penhorar-me e se as não repito é porque a modestia as apegou da minha memoria só deixando sim a maior impressão na minha gratidão."

Terminava assim uma primeira etapa das relações entre a Russia imperial e o Brasil republicano sem que se registrasse qualquer avanço para reconhecer o novo regime brasileiro.

\section{O RESTABELECIMENTO DAS RELAÇÕES BRASIL/RÚSSIA}

Depois de setembro de 1890 , quando se realizaram as eleições para a constituinte no Brasil, a maioria dos estados europeus, reticentes a princípio com o novo regime brasileiro, começaram a ceder, encaminhando satisfatoriamente as negociações para o reconhecimento que, de um modo geral foram concluídas até 1891.

O governo russo, ao contrário, sustentou um constrangedor silêncio, mantendo-se assim até meados de 1892, portanto a situação deixada por Teixeira de Macedo em 1890 pouco se alterara.

O primeiro passo para reverter este quadro aconteceu somente em maio de 1892 quando Giers, em resposta a uma consulta brasileira, informa que o Czar estava disposto a receber um novo representante da república. Para tanto foi necessário que Serzedello Corrêa, Ministro das Relações Exteriores do Brasil, historiasse sobre os acontecimentos transcorridos desde a proclamação da república, passando pela promulgação da constituição e eleição de Deodoro da Fonseca em fevereiro de 1891, até a renúncia do mesmo em novembro do mesmo ano. ${ }^{7}$

Já em 8 de agosto de 1892, Francisco Regis de Oliveira, designado pelo governo brasileiro para representá-lo na Rússia, notificava que tinha sido recebido oficialmente pelo Czar que, surpreendentemente afirmara que "havia extranhado não ter-the o nosso Governo facilitado a occasiâo de reconhecer-lo mais cedo". Acrescentou ainda que "não proveio delle a demora do reconhecimento da república pois só ultimamen. te recebeu a communicação official da sua instituição legal." 8 Ante estas declarações deve-se levar em conta algumas situações já anteriormente analisadas. O governo russo, assim como o de outros países, havia recebido a circular de Quintino Bocayuva de 19 de novembro de 1889 , na qual se participava a proclamação da república e se pedia o seu reconhecimento. Posteriormente são conhecidas as gestões de Teixeira de Macedo no sentido de obter da Rússia o reconhecimento da república tendo inclusive informado ao Brasil, em 21 de dezembro de 1889, que Giers, depois de estar com o Czar, the comunicara que seu governo não pretendia ser nem o primeiro nem 
o último a reconhecer república. Tais evidências demonstram que a resistência em relação ao reconhecimento nâo advinha do desconhecimento oficial sobre os acontecimentos brasileiros como afirmara o Czar à Regis de Oliveira em agosto de 1892. A atitude do Czar pode ser melhor entendida se levarmos em consideração que a própria consolidação da república brasileira ainda nâo se efetivara. Além disto, a existência de D. Pedro II no exílio levava a velha e tradicional monarquia russa a ter certos pruridos em relação ao regime que depuzara o prestigioso monarca. Já em 1892, em pleno governo de Floriano Peixoto, a situação já era outra: o regime se consolidava e, no ano anterior, a 5 de dezembro, falecera em Paris, D. Pedro II.

Facilitavam-se assim as novas negociações para o reconhecimento Russo que terminou sendo oficializado em 26 de maio de 1892.

\section{NOTAS}

1 - Em oficio à Quintino Bocayuva, Ministro das Relaçòes Exteriores do Brasil, escreve Teixeira de Macedo de São Petersburgo, em 16 de dezembro de 1889: "O Ministro de S. M. que honra-me com a sua consideraçào, para nào empregar a palavra amizade, parecia evitar de dar-me qualquer resposta." [refere-se a Nota brasileira relativa à proclamação da república e pedido de reconhecimento]. Arquivo Histórico do Itamaraty. Dossier sobre o reconhecimento da república-1895-1896-339/15A (Os demais documentos citados a seguir pertencem ao mesmo arquivo e dossier)

2 - Teixeira de Macedo à Quintino Bocayuva. São Petersburgo, 21 de dezembro de 1889, até que se indique o contrário.

3 - Oficio à Quintino Bocayuva. São Petersburgo, 11 de janeiro de 1890, até que se indiquem o contrírio.

4 - Oficio à Quintino Bocayuva, São Petersburgo

5 - Por diversas vezes Teixeira de Macedo insiste em que não tinha condições de saúde para permanecer na Rússia. Em 11 de janeiro de 1890 escreveu a Quintino Bocayuva: "Por minha parte cada dia torna-se mais urgente deixar este clima que esti a consumir-me a saúde e a minar-me as forças. Ha mais tempo representei para que fosse-me confiado outro posto $\mathrm{e} V$. Ex. deve saber que estava em vespera de ser attendido. O que digo porem em relação ao interesse do serviço é independente do meu e se fallo simultaneamente nos dois é porque não quero que $\mathrm{V}$. Ex. veja no que digo uma insinuação que eu procure desfarçar. Ainda tenho bastante patriotismo para sacrificar-me pelo meu paiz mas era preciso que elle tivesse proveito disso e tal nào é o caso. " Em 27 de janeiro de 1890 volta Teixeira de Macedo a escrever: "Não posso deixar de insistir em chamar a atenção de V. Ex. sobre a incoveniencia de prolongar esta minha posição I de permanecer na Rússia sem ser reconhecida a república] quando sem comprometter as relaçòes e muito airosamente se poderia pôr-lhe termo concedendo-se me uma licença por motivo de falta de saude." 
6 - Ibidem nota 4

7 - Oficio de Serzedello Corrèa à Giers, Rio de Janeiro, 22 de abril de 1892.

8 - Oficio à Custódio José de Mello, Ministro das Relações Exteriores do Brasil. São Petersburgo, 8 de agosto de 1892 . 